\title{
Fineman, vulnerability and the myth of autonomy
}

\author{
Ian Cummins
}

\section{Introduction}

From a critical social work perspective this chapter will consider the work of the American feminist legal scholar, Martha Fineman $(2004,2008)$. It will argue that Fineman's challenge to the deeply engrained notions of individualism can be the anchor for the recasting of a more egalitarian and responsive social state. The chapter will briefly examine the notions of individualism that are such a key feature of neoliberalism. It will go on to outline the main themes in Fineman's argument and her notion of "the vulnerable subject". She argues that vulnerability is a constant and universal feature of the human condition. If we recognize this, there are significant implications for the role of the state, particularly in the field of social welfare. The chapter concludes by arguing that Fineman's work can play a key role in the reinvigoration of societal institutions that focus on the wellbeing of citizens rather than the management of marginalized populations.

\section{Neoliberalism, individualism and the welfare state}

Two key beliefs are at the heart of neoliberal ideas: the supremacy of the market (as the most effective means established for the distribution of resources), and a belief in liberty (defined here as freedom from state or other interference) as the supreme social and political value. Hayek ( (Hayek, 2001 ) argued that the role of the state should be to ensure that markets could operate - so, for example, a process for enforcing commercial contracts is needed, and personal and company taxation needs to be as low as possible, as this will increase incentives for individuals to work harder as they will receive greater rewards. It is also argued that low taxation rewards entrepreneurs and risk takers. One of the undoubted successes of neoliberalism has been the extent to which its key ideas - efficiency 
of the market, and a belief that success is the result of individual hard work have become so deeply entrenched. From the 1970s onwards, think tanks have had a key role to play in this process. For example, the Heritage Foundation and the Cato Institute in the US and the Policy Exchange in the UK.

Individualism is a key trope of all forms of liberalism. Within neoliberalism, the commitment to individualism reaches new heights. The political successes of the Reagan and Thatcher administrations were based, in part, on the way that these ideas were communicated. Free markets were presenting as allowing individuals to make decisions, and choices free from state interference. Both Thatcher and Reagan were elected on platforms that saw government as the problem rather than the solution. Neoliberalism seeks to expand markets or extend market forces to areas of the economy or social provision previously considered as standing outside of it. This is a mixture of libertarian objections to the state having a role in these areas (Nozick, 1974) and economic ones. Neoliberalism argues that the discipline of the market and competition should be applied to state institutions. It is one of the reasons that their ideas have become so popular as most of us see choice and the right to exercise it as positive.

The concept of individualism raises important questions for professions such as social work that are explicitly concerned with notions of social justice. As a result, social work often finds itself at odds with the prevailing zeitgeist although it should be said that the profession often struggles or fails to acknowledge this. In the economic sphere, individualism is based on the largely mythical figure of the self-made man (or very occasionally woman). The language of radical identity and feminist politics of the 1960s has been successfully colonised by neoliberalism so that such issues are recast as issues of individualism (Fraser, 2013). For neoliberalism, inequality is a fact of human life - put simply, we are not equal - not in terms of the law or civic rights, but in terms of skills and abilities. Any attempts to overcome inequality are to be opposed because they are doomed to fail as a result of this basic fact. 
The neoliberal conception of the state is most clearly enunciated in Nozick's (1974) Anarchy, state and utopia. In this schema, the state should act as a "night watchman' for wider society. The role is to ensure that law and order is maintained, but any other state interventions are viewed as either a restriction on individual liberty or interference in the workings of the market, or a combination of the two. The notions of choice and individualism are clearly inextricably linked. They are at the root of the neoliberal attack on the welfare state. Thinkers on the Right are wary of the welfare state for economic and social reasons. The welfare state can only be funded by taxation either on corporations or on individuals. Either route distorts the markets, acts as a drain on individual initiative and entrepreneurship, and is wasteful. The welfare state is seen as either creating dependency or excusing anti-social behaviour. Neoliberalism is not opposed to charity or philanthropy - how people choose to spend their money is a matter of choice. Neoliberals object to this becoming a state-run activity. The discourse of the moral failings of the poor has a long and undistinguished history (Welshman, 2013). In this context, it is most closely associated with Murray and the term 'the underclass' (Murray, 1990). Murray, incidentally, heavily supported and given publicity by the IEA, argued that the welfare state had created a new class, the underclass. For Murray and others, welfare professionals such as social workers, with their commitment to 'woolly ideas' such as social justice, are often seen as part of this process.

Neoliberalism has come to define the terms of the debate in economic, cultural and political spheres. Neoliberalism has pushed out other ideas. Neoliberalism thus becomes a political project not simply an economic one. One way of conceptualising this political (re)birth of neoliberalism is to see it as a reaction against the Statism of the 1960s and 1970s. From this perspective, the state had taken on too great a role, not only in terms of the economy - nationalised industries and regulation - but also in the daily lives of citizens. This is where the social and economic come together. The shift that occurred in the 1980s/90s, the 'hollowing out' of the state, saw a new set of arrangements for governance established, including a new range of regulators and inspection regimes for public bodies (Skelcher, 2000) . The development of 'new public management' (NPM) was an attempt to introduce some elements of the market, such as competition, to 
public services. In this model, it was important that there was a purchaser/provider split to break up perceived monopolies (Pollitt, 1999). Policies were written in the language of consumer choice. NPM led to the development of an audit culture, so that in health, education and other areas, an organization's performance was measured against a series of Key Performance Indicators (KPIs), which for many was seen as an attack on their professional independence and autonomy. It also created a huge bureaucratic structure to manage the data (Pollitt, 1999).

The late Stuart Hall (1932-2014) proved to be one of the earliest and most perceptive critics of neoliberalism. He is credited with coining the term Thatcherism. One of the most important themes in Hall's work is that an economic explanation is never in and of itself. The rise of Thatcherism and neoliberalism cannot be explained solely by the economic crisis of the mid 1970s, this is undoubtedly a very important factor but on its own, it does not offer a complete explanation (Hall, 2011). The role of the state is a key question in the discussion of any political ideology. Political theory at its core is concerned with the relationship between the individual and the wider society. Neoliberalism's key intellectual thinkers Hayek, Friedman and Nozick are fundamentally committed to a "small state". Neoliberalism is committed to a version of personal freedom where this is essentially defined as freedom from state interference. The economic and political are, thus intertwined.

The Right has been opposed to the modern welfare state since its creation. In the post war period, Conservatives reached some sort of grudging acceptance of the main features of the new welfare state. There were always Conservative thinkers who were concerned that the welfare state generated dependency (Cummins, 2018). However, since the election of the first Thatcher Government in 1979, the anti-welfarist position has been much stronger. The Right has mounted a protracted "war of position" against the key features of a universalist welfare state (Garrett, 2017). One key element of this is the way that the term welfare has come to have overwhelmingly negative connotations. This process has been led by an unholy alliance of academics, right wing think tanks and op-ed in Conservative newspapers (Wacquant, 2009). The development and use of the 
term "sink estate" is a case study analysis of these processes (Slater, 2018). Slater demonstrates the way that this term has moved into the political and media mainstream and is used to attack the fundamental notion of social housing. In the American context, welfare has become a "dog whistle" term which politicians can use to make racist claims and statements whilst at the same time claiming that they are not talking about race (Haney-Lopez, 2015).

In the conservative paradigm, poverty as a moral issue in the sense that poverty is the result of the moral failings of those living in poverty (Mead, 1992) (Murray, 1990).Poor people make poor choices and are then rewarded for them by the welfare state. These ideas are most closely associated with Murray (1990) and his concept of the "underclass". Murray argues that the welfare state because of its generosity has created a class that is cut off economic, socially and very importantly in his terms morally from the wider society. In this schema, the welfare state rewards rather than punishes anti-social behaviour. A new form development a new form of political economy has developed which can be classified as a strengthening of 'anti-welfare commonsense' (Jensen, 2015). The problems of the welfare state is not its minimal and exclusionary nature but that it is overgenerous and too expensive. Therefore, the issue to be solved is not poverty, but welfare dependency (Peck, 2002). The welfare state has been in a state of crisis since the early 1970s, and this crisis is seen through one of two lenses - the creation of dependency or a government fiscal crisis that is used for justification for retrenchment (Mary, 1998).

\section{Fineman and the vulnerable subject}

This section will examine Fineman's notion of "the vulnerable subject". Fineman (2008) posits the notion as an alternative to the "liberal subject" which she argues is deeply embedded in not only political and legal theory but also in social and cultural norms. This section begins by outlining the liberal subject and the associated discourse of human rights, before going to explore Fineman's key ideas. 
There has been a significant rise in the interest in and use of the term vulnerability. However, it is a term that is rather loosely or poorly defined. Within social work field, No Secrets statutory Guidance which covered adult safeguarding, defined 'vulnerable adult' as a person: "who is or may be in need of community care services by reason of mental or other disability, age or illness; and who is or may be unable to take care of him or herself, or unable to protect him or herself against significant harm or exploitation". The Care Act 2014 has replaced this definition. This legislation uses the term 'an adult at risk.' An adult at risk of abuse or neglect is defined as someone who has needs for care and support, who is experiencing, or at risk of, abuse or neglect and as a result of their care needs - is unable to protect themselves. These uses represent an individualisation of the term. They, perhaps, unintentionally, focus on a deficit model looking at ways or circumstances, in which, individuals might be or become vulnerable. This approach also leads to the identification of vulnerable populations or groups.

The use of the term "vulnerability" has its roots in the biological and life sciences. In the 1980s, it was a term that was rarely used. It first appeared more widely in the 1990s but since 2000, there has been an explosion in the use of the term . The term originates in risk research which examines the causes and impacts of natural disasters. It was used as a way of examining the ways, in which, structures and institutions may prevent or add to the consequences of a natural disaster. For example, an earthquake is a potential natural disaster. In considering the risks or vulnerability of a region, one would need to consider not only the likelihood of such an event, alongside the impact of the size of the quake. In addition, the physical and social infrastructure will be a factor in the calculation of any potential impact. This will include an analysis of the design of the buildings and their ability to resist shocks as well the state resources that would be available to respond to such an event.

Hannappi et. al. (2015) in their analysis of the development of the use of the term identified 10, 632 articles where it occurred. Vulnerability has become a concept that is central to psychology, sociology and social work. Spini et. al. (2013) see the term as an interdisciplinary one. The reason that it can be used across so 
many disciplines is that there is no real accepted definition. In broad terms, it is concerned with the lack of resources that individuals or communities possess. This means that individuals or groups are at increased risk of experiencing stress factors. They then face greater challenges in coping with these stressors or recovering from their impact. One can see the application of this model in the exploration of the links between poverty and mental health (Cummins, 2018).The links between socio-economic factors and mental health play out in a number of complex ways. Psychosocial factors such as ongoing acute stress can have detrimental impact on an individual's mental health (Wilkinson, 2017). People from marginalised groups, for example asylum seekers and refugees or those who have experienced other forms of trauma, are more vulnerable to the development of mental health problems. The stresses of the daily experiences and pressures of living in poverty such as debt, worry about being able to cope with emergencies and precarious accommodation can all contribute to poor mental health (Elliott, 2016).

The "risk society" (Beck, 1992) has had a significant influence on social work practice. Risk inevitability requires some form of assessment - how else could it be identified, followed by plan to tackle those risks. Organisations then need to audit these processes. Finally, there needs to be an outside inspection process (Webb, 2006). Vulnerability can be viewed as something of a shift from risk - the two are clearly linked. However, vulnerability is used in more paternalistic terms in the social welfare field. Originally, a much more dynamic and shifting term - a way of identifying risk factors within eco and social systems, it is used within social welfare in quite different ways. It becomes a quality - individuals are deemed "vulnerable". There is a danger that this assessment then becomes the justification for a paternalistic form of social work and the restriction of rights and choices.

\section{The liberal subject and the discourse of rights}

The modern political discourse and framework of human rights has its roots in the response to the atrocities of World War II (Habermas, 2010). The UN Declaration of Human Rights states in Article 1 that 'All human beings are born 
free and equal in dignity and rights' (United131 Nations General Assembly, 1948). These abuses of human rights are violations of human dignity. An agreed common set of moral values that recognise the equal dignity of all human beings that legal protections against their violation that rights can be established. The modern notion of human rights can be read as a recasting of Kant's (1996) categorical imperative that every person should be viewed as an 'end in themselves'. This approach is in contrast to utilitarianism and other forms of consequentialism.

The post-Second World War discourse of human rights is contrasted by Habermas (2010) with the 19th-century development of the liberal rights of freedom of association and religion, protections against arbitrary arrest, and so on. This set of democratic rights of participation or classical civil rights act as a buffer against the intrusion of the state into the private sphere as well forming the basis for the creation of the realm of civil society. The egalitarian and universal rhetoric cannot not obscure the fact that these civil rights are and were enjoyed disproportionately. Women and minorities being two obvious examples of groups that were effectively excluded from full social citizenship. The current notion of dignity has at its root an explicit egalitarianism that does not allow for exclusion - unless one regards certain groups of people as non-human, this is a logical fallacy. Habermas (2010) argues that any appeal to current human rights discourse is based on a concept of human dignity. The outrage at the abuse of political prisoners, the use of torture and the treatment of asylum-seekers and immigrants is the result of a response to the humiliations that these violations of human dignity entail.

The classical civil rights of political liberalism only acquire equal value for citizens when they are accompanied by social and cultural rights (Rawls, 1971). Rawls' concern with social inequalities meant that he saw a danger in whole groups being effectively excluded from the broader society and culture. Dignity provides a basis for the equal respect of citizens (Fraser, 2010) Fraser argues that the claim for equal treatment on the basis of identity must have within it a simultaneous claim for redistribution for it to have value. Dignity is both a powerful but also a vague concept (Dworkin, 1995). This is part of its attraction, 
but also, perhaps, part of its weakness. Dworkin also added that any notion of human rights had to accept that dignity would be at its core Dignity is afforded because of one's status as a human being. In this sense, the notion of dignity can act as a link or a bridge between the individual and wider society.

A further challenge to the notion of the human rights discourse is most forthrightly expressed in the work of the radical French philosopher, Alain Badiou. He remains strongly committed to ideas of the 1968 movement that challenged the key notions of Western liberal capitalist democracies. His critique of capitalism sees it not as a progressive force that led to the establishment of liberal rights, but as a form of nihilism (Badiou, 2015). He argues that modern discourse, based as it is on individualism, is actually an adjunct to neoliberalism. Modern social work ethics reflect the post-modern turn and its concern with identity, diversity and difference (Webb, 2009). Badiou argues these notions lead to a conflict between an expressed universalism derived from Kant and Habermas, and respect for the Other. The result is that Western liberalism will only respect what it sees as acceptable forms of difference. Badiou (2015) sees human rights discourse as essentially duplicitous - human rights are accorded to those who best fit the Western liberal ideal. From this radical perspective, the politics of human rights leads to a new form of US-led imperialism in international politics. On the domestic front, a mixture of communitarianism and identity politics leads to the marginalisation of class-based claims for redistribution.

The Trump and post Brexit Referendum politics of 2016 in both the UK and US, mark a retreat from the development of the sort of universal and international forms of civic cohesion that Habermas (2010) envisages emerging from the broader human rights discourse. The retreat into or a return to a politics that is essentialist in response to issues of race, gender and sexuality. The most highprofile proponents of this politics - Trump and Farage - revelled, personally and politically, in this challenge to the alleged liberal orthodoxy seems to add to rather than detract from their wider appeal. There is a danger of falling into a self-defeating pessimism in response to some of these developments. This would 
undo or perhaps fail to defend the progress that has been made in terms of civil, political and social rights

\section{The liberal subject}

The notion of the liberal subject is at the heart of much contemporary political theory and debate. Individualism, as noted above, is one of the key tropes of neoliberalism. In this model, the market functions because of the decisions that individuals make. Choice is one of the key doxa of neoliberalism. Doxa is derived from Greek and means " a commonly held belief”. However, Wacquant (2009) uses the term to mean words or phrases that used to set the boundaries of or structure debate. Flexibility, individualism alongside other phrases such as market, choice and freedom have become deeply engrained in public discourse. One of the impacts of doxa is that they are repeated so often that they are used almost uncritically. They also mean that it is difficult to shift the terms of the debate. Arguments for state intervention are often presented as one seeking to limit individual choice - who can be against people making decisions for themselves. This shows the power of doxa - the argument here is that choice can be and is exercised differently by individuals and groups depending on their social, economic and political status.

The liberal subject is an idealised individual citizen. Such citizens are independent, autonomous adults. In this model, the wider world is characterised by individual not broader social responsibilities. Fineman (2004) notes that a range of social arrangements and institutions that have huge impact on individual lives and life chances are regarded as private. The most significant of these is the family. Fineman argues that such an approach is deeply entwined with other ideological perspectives, such as a belief in free market capitalism and the notion of meritocracy. When taken together, these notions present almost any state intervention as a violation of individual liberty and the first step to a totalitarian state. Fineman is writing from a US perspective where the social state has traditionally been on weaker foundations than its European counterparts. However, it is important to note that one of the success of neoliberalism has been the way that such anti-statist ideas have become more widely adopted - by both 
the libertarian Right and Left. Fineman (2004) suggests that the results are that liberty has become more highly valued than equality. The role of the state and the law, in particular, becomes to decide between competing individual claims and ensure fair treatment.

\section{More on the vulnerable subject}

Fineman (2008) argues that there is a need for a more equal and responsive state. She sees vulnerability as a universal and constant feature of the human condition. This can then be the starting point for the development of a more responsive state. Vulnerable people should be the focus of the policies that states develop, as this would result in greater equality. Fineman (2004) argues that current social and welfare policies start from the position or assumption of the liberal subject an imagined autonomous individual.

Fineman suggests that autonomy is a myth - we all need or will need some care at some point in our lives. No one would make it to adulthood without the support of other members of society. Fineman notes that we tend to emphasise capacity, independence or autonomy. The term 'vulnerability' across welfare and other social policies. However, it is not used in the same sense that Fineman used it. It becomes an almost all-encompassing term that can be used as a justification for intervention. It is fundamentally a paternalistic approach. In Fineman's work, it is the basis for a mutual understanding or reciprocity. The focus on individualism ignores or seeks to set aside the basic conditions of mutuality that are required for social systems to function. This is particularly the casein the provision of care, 'care' being used in its broadest sense here. Current systems privatise our collective responsibility for care. Fineman is writing in the US context, where there has never been a welfare state of the post-war social democratic style that neoliberalism so opposes. However, the arguments she presents are increasingly relevant to the European context where the social contract is under increasing, and possibly terminal, pressure.

Fineman argues that vulnerability is different for different people because of different 
positions in a complex web of economic and institutional relationships. These relationships is not only the result of economic power and capital. It requires a consideration of social, cultural and historical factors. Social institutions and organisations create a range of assets such as material wealth and property. Our access to the enjoyment of assets depends on our position within these patterns of relationships. All of us are vulnerable and dependent on others to exist. By failing to acknowledge our common vulnerability, Fineman argues, we lose sight of the ways in which power and privilege operate, providing support and protection to the wealthiest members of society. These protections are not available to more marginalised members of society.

Fineman sees the current state as 'a restrained state'. The notion of the private (family) serves as a significant psychological, cultural and legal barrier. It means that the institutions of the welfare state are kept at arm's length. These barriers make the ensuring equality more difficult. Fineman's work suggests that the state has a key role to play in the creation and maintenance of a more equal society. The state has been prevented from acting as the principal monitor of an equal society. The current legal and formal policies of equality have failed to achieve their aims. Formal legal equality does not:

- protect against subordination and domination.

- protect against all forms of discrimination - for example, on grounds of sexual orientation or disability.

- formal equality policies are based on the existing allocations of resources and power

- such policies do not hold the state accountable.

Fineman argues that state faces a clear obligation not to privilege to any group of citizens. However, this involves challenging some deeply embedded cultural norms. One of these is the notion that citizens are autonomous individuals. This notion of autonomy is a form of rugged individualism that excludes dependency as weakness. This is despite the fact that it is actually unavoidable. Fineman concludes that society should be egalitarian. In a more egalitarian society, the state would and should be more responsive. Fineman's work can be part of a shift 
in attitudes in these areas and of reclaiming the social sphere. The attraction for social work is that this is clearly an egalitarian ethos. In addition, it calls for a reinvigoration of the public provision of care as the privatisation of this sphere serves to entrench already existing inequalities. There is a danger that the use of the term 'vulnerable' becomes subsumed in a culture that limits rather than extends rights.

\section{Social work and vulnerability}

Neoliberal ideas have been able to set the agenda across social, political, economic and cultural fields (Giroux, 2011). "Hyperindividualism" leads to a loosening and weakening of social and community ties (Bauman, 2008). Social work performs a key role in protecting and supporting vulnerable people or groups. Vulnerable is not used in the Fineman sense. Social work provides or attempts to provide a response to the failings of or gaps in the market. As noted above, successive governments have attempted to introduce the market or elements of it to the organisation and provision of social welfare services. Critics of social work and the welfare state more broadly from both the left and the right argue that the fundamental nature and role of welfare systems is obscured by this rhetoric of care. For the left, social work, is essentially a disciplinary activity that helps to shore up rather than challenge structural inequalities. For the right, social work is part of the bloated state bureaucracy that creates dependency and stifles individual freedom. There is a tension between the declared ethics and values of social work as a profession and the context in which practitioners carry out their roles. These tensions and contradictions are not new and have been a feature of social work and modern welfare regimes since their emergence as a response to modern urban capitalism.

The key question is how we can use insights from Fineman for critical social work? In turning notions of vulnerability on their head, Fineman is arguing for more egalitarian society with a stronger social state. The basis of this social state would be a recognition of our mutual dependence. In the UK context, this means a restatement and reinvigoration of pro social values and a rejection of neoliberalism. The impact of austerity has been to significantly reduce the 
resources of the social state whiles at the same time increasing the need for social welfare services. One clear example of this is the increase in the use of foodbanks (see Pollock chapter in this volume). The UN Committee on Economic, Social and Cultural Rights published a devastating report on the impact of austerity and welfare reform in the UK. The report concluded that the Government had failed to meet its obligations under human rights policies. The report highlighted increases in homelessness, poor provision of mental health care and increased discrimination against asylum seekers and refugees. The Windrush scandal highlighted that the creation of a so-called "hostile environment" towards immigrants was not some unintended side effect of government policy - it was the policy. The same could be said of the impact of austerity and welfare reform.

Fineman's work can be a starting point for arguing for the development of a new model of a social and welfare state. It is important that in highlighting the impact of austerity we do not fall into the trap of viewing the welfare state of the post war period through rose tinted spectacles. It was clearly far from perfect. Her notion of vulnerability starts from the point of the need to acknowledge a common element of our humanity - the fact that we all require care and are dependent on others at some point in our lives. The vulnerable subject is presented in contrast to the disembodied liberal subject that is the focus of much legal, policy and philosophical discourse. Vulnerability as a term has become one of the doxa of the social work profession. I would argue that it is used in a way contrary to its original meaning. It becomes a way of actually restricting choice and denying agency of individuals. Fineman's' notion of vulnerability can be viewed more as a statement of an ethical position. It can be thus used as a justification for the reestablishment of the social sphere and the invigoration of the public provision of care. This part of a process that seeks to develop a more critical and relational rather than functional form of social work practice.

\section{Conclusion}

It would be foolish or naive to ignore the appeal of some of the key underpinning ideas of neoliberal political thought. As Hall (2011) observed one of the key skills of the Thatcher and Reagan administration was to communicate to the electorate 
a growing dissatisfaction with the state and state bureaucracies. He goes on to argue that for many groups within the electorate, they did not see state agencies, including social work, were seen as a punitive or obstructive. Individualism and choice became powerful mantras. They remain deeply engrained cultural and social tropes. As Fraser (2013) notes neoliberalism co-opted some of the language of the Left's challenges to the welfare state. The result is the notional consumerism that we see in health and social welfare today. Patients are regarded as consumers. Social work continues to struggle to find appropriate terms. Service user, the most commonly used term, remains problematic.

Fineman's notion of vulnerability can be the starting point for challenging the notions of individualism and choice. This is not to say that we should not treat people as individuals or recognise that they have a right to exercise choices. It is rather a recognition of the limits of the ultimate utility of these concepts. Choices can only be exercised within a social context. This must include the resources available but also the social status of the individual making the choices. The right and power to make choices is not distributed amongst individuals. Without economic rights then many groups are unable to exercise political and social rights thus becoming effectively disenfranchised (Somers, 1994). Fineman's work is a rejoinder to the disembodied liberal subject of much political theory.

Fineman argues vulnerability is universal, constant and deeply rooted in the human condition. This is a contrast to the usual and widely used notion of vulnerability that exists in health and social welfare services. This notion seeks to identify those factors that might make an individual vulnerable. This logically then leads to the creation of vulnerable population and groups Fineman's focus is to argue that we are or should be seen as vulnerable subjects. She has argued that the notion of autonomy that underpins much of view of the worth of individualism is a myth. The cultural focus on individualism hides the social reality of our interconnectedness. We share a messy dependency. The reality is that we all need or will need some care at points in our lives. Vulnerability may be different for different people at different points in their lives. There is a danger that the current use of the term means that vulnerability becomes a paternalistic term. Ironically, a way of denying agency or choice. It is, after all, vulnerability 
is identified by professionals. It is not an identity that one can claim for oneself. The term "vulnerable" is subsumed in an organisational and professional culture that limits rather than extends rights. Fineman's use of the term is radically different. It is a basis for genuine reciprocity and a call for a more responsive state and equal society. This is the roots of its attraction to critical social work.

\section{References}

Badiou, A. (2015). Theoretical writings. London: Bloomsbury.

Bauman, Z. (2008). The art of life,. Cambridge: Polity Press.

Beck, U. (1992). Risk society: Towards a new modernity,. London: Sage.

Cummins, I. (2018). Poverty, inequality and social work. Bristol : Policy Press.

Cummins, I. (2018). The impact of austerity on mental health service provision : a UK perspective. International Journal of Environmental Research and Public Health, , 11-45.

Dworkin, R. (1995). Life's dominion, London : Harper Collins.

Elliott, I. (2016). Poverty and Mental Health: A Review to Inform the Joseph Rowntree Foundation's Anti-Poverty Strategy. York : Joseph Rowntree Foundation .

Fineman, M. (2004). The autonomy myth a theory of dependency,. New York : New York Press .

Fineman, M. (2008). The vulnerable subject: anchoring equality in. Yale Journal of Law and Feminism, 1-25. 
Fraser, N. (2010). Who counts? Dilemmas of justice in a postWestphalian. Antipode, 281-297.

Fraser, N. (2013). The fortunes of feminism: From women's liberation to identity politics to anti-capitalism,. London: Verso.

Garrett, P. (2017). Welfare Words. London : Sage .

Giroux, H. (2011). Neoliberalism and the death of the social state:Remembering Walter Benjamin's Angel of History. Social Identities:Journal for the Study of Race, Nation and Culture, 587-601.

Habermas, J. (2010). The concept of human dignity and the realistic utopia of human rights. Metaphilosophy, 468-480.

Hall, S. (2011). The neo-liberal revolution. Cultural studies, 705-728.

Haney-Lopez, I. (2015). Dog whistle politics: How coded racial appeals have reinvented racism and wrecked the middle class,. Oxford: Oxford University Press.

Hayek, F. (2001). The road to serfdom. London : Routledge (Classics) .

Jensen, T. a. (2015). "Benefits broods": The cultural and political crafting of antiwelfare common sense',. Critical Social Policy , 1-22.

Mary. (1998). Welfare: Needs, rights and risks,. London : Routledge.

Mead, L. (1992). The new politics of poverty: The nonworking poor in America. New York : Basic Books .

Murray, C. (1990). The emerging British underclass. London : Institute of Economic Affairs .

Nozick, R. (1974). Anarchy, state and utopia. Oxford : Blackwell .

Peck, J. a. (2002). Neoliberalizing space. Antipode, 380-404.

Pollitt, C. a. (1999). Public management reform: A comparative analysis,. Oxford : Oxford University Press .

Rawls, J. (1971). A theory of justice. Cambridge MA : Harvard University Press.

Skelcher, C. (2000). Changing images of the state: Overloaded,hollowed-out, congested. Public Policy and Administration, 1-19.

Slater, T. (2018). The Invention of the Sink Estate: Consequential Categorization and the UK Housing Crisis. The Sociological Review, 1-22.

Somers, M. (1994). Rights, relationality, and membership: rethinking the making and meaning of citizenship. Law \& Social Inquiry, 63-114. 
Wacquant, L. (2009). Punishing the poor: The neoliberal government of social insecurity. Durham NC : Duke University Press .

Webb, S (2009). Against difference and diversity in social work: The case of human rights. International Journal of Social Welfare, 307-316.

Webb, S. (2006). Social Work in a Risk Society . Basingstoke: Palgrave Macmillan .

Welshman, J. (2013). Underclass: A history of the excluded since 1880,. London: Bloomsbury.

Wilkinson, R. a. (2017). The enemy between us: The psychological and social costs of inequality. European Journal of Social Psychology, 11-24. 